\title{
Fragility in the elderly participants of coexistence and health promotion groups in the aging
}

\author{
Bartolomeu Fagundes de Lima Filho1, Diego de Sousa Dantas ${ }^{2,3}$, Fernanda Diniz de Sá3,4, \\ Luciane Paula Batista Araújo de Oliveira ${ }^{3,5}$.
}

\begin{abstract}
INTRODUCTION: The frailty syndrome is a complex condition that permeates the life of the elderly, with the decrease of the homeostatic reserve of the organism and loss of resistance to the stressors, caused as results of many factors, but mainly by sarcopenia. Such syndrome makes the elderly vulnerable to illness and may lead to terminal stages of life if there is no adequate treatment. OBJECTIVE: To evaluate the influence of the factors related to the frailty phenotype in the occurrence of this in participants of groups of coexistence and health promotion of the city of Santa Cruz/RN. METHOD: This is a descriptive, associative and transversal of quantitative approach study with 60 elderly. The socioeconomic condition and the fragility phenotype was evaluated. RESULTS: the mean age of the sample was 66.1 years $(S D=5.08)$. Most of them (53.3\%) are in the age group of 60-69 years, does not have a partner (63.4\%) and are illiterate $(58.3 \%)$. In the mentioned morbidity, 42 (70\%) reported some morbidity and hypertension was more prevalent in the sample (53.3\%), followed by diabetes (20\%) and osteoporosis (18.3\%). Four elderly were fragile, forty-nine were pre-fragile and seven were non-fragile. There was a significant correlation in unintentional loss of weight $(0.017)$, exhaustion $(<0.001)$ and slowness in gait $(<0.001)$ in the occurrence of pre-frailty. CONCLUSION: the prevalence of pre-frailty indicators in the investigated groups indicates warning signs so that actions more strongly linked to the prevention of this aggravation become a priority in the planning of the undertaken interventions in groups. Participation in social groups has a protective effect in the prevention of frailty in the elderly.
\end{abstract}

KEYWORDS: Social Determinants of Health; Elderly; Frail Elderly.

\section{INTRODUCTION}

The rapid growth of the elderly population in Brazil shows special attention and seeks the scientific support to deal with this context. Population aging is due to an arsenal of socioeconomic changes, propitiating changes in the age pyramid of Brazil and the world. The fact that this process has occurred in an accelerated way in Brazil generates the lack of a support for more effective care directed to this population, especially for the portion at risk of frailty. ${ }^{(1)}$

Thus, frailty in the elderly is a condition widely discussed today, mainly because it is a multifaceted aggravation. It has already been based on several theoretical domains, often grouped in the physical, cognitive and social dimensions..$^{(2-3)}$ The current concept states that this is a complex syndrome which occurs with the reduce of the homeostatic reserve capacity of the organism and decrease of the resistance to the stressors, causing reduction of the physiological systems and leaving the elderly vulnerable, allowing numerous clinical problems. $^{(4)}$
Therefore, the aging triad most associated with frailty permeates sarcopenia, neuroendocrine dysregulation and immune dysfunction ${ }^{(3,5-7)}$ Fragility is a syndrome, so it is characterized by its phenotype, and 5 items are conferred for classification, which is unintentional weight loss, self-reported fatigue, reduction of grip strength of dominant hand, reduction of physical activity and reduced gait speed..$^{(2,8,7)}$

In addition, because it is a multidimensional condition, the impact of social participation on the maintenance of capacities and the relationship between these and the risk differentials for frailty, puts in focus the concept of Social Determinants of Health (SDH). Discussed among the world nations, these determinants reveal personal and working conditions, singular or group, related to the health situation of the individual or specific group, being linked to social, economic, cultural, ethnic-racial, psychological and behavioral factors capable of influencing health problems and risk factors. ${ }^{(9)}$

\footnotetext{
Corresponding Author: Name: Bartolomeu Fagundes de Lima Filho. Institution: Federal University of Rio Grande do Norte (UFRN), campus of Faculty of Health Sciences of Trairi (FACISA). E-mail: bartolomeu_fagundes2@hotmail.com. Address: Avenida Rio Branco, sem número, centro, Santa Cruz, RN, Telephone: +55 (84) 9-9419-7593.

1Undergraduate of the Physiotherapy course, Federal University of Rio Grande do Norte (UFRN), campus of Faculty of Health Sciences of Trairi (FACISA), Santa Cruz (RN), Brazil.
} 
Given this, among the broad spectrum of DSS components stand out the social and community networks for aging and these two items have been shown to be the most relevant factors for the quality of life of the elderly. ${ }^{(9)}$ The social groups and health promotion for elderly, developed in community places or in Basic Health Units (BHU), from the development of primary care or in conjunction of this with SUAS (Sistema Único de Assistência Social) has been shown to be a successful strategy, since the quality of life can be influenced directly by their participation in the social networks. The activities performed there make possible the creation of a practical arsenal of improvement of global health conditions in an elderly. The cognitive and functional effects are the best reported, relating self-esteem, improved identity and quality of life. ${ }^{(10)}$

In this way, the screening of the risk for frailty occurrence in elderly in groups of coexistence and health promotion may favor the orientation of health interventions in their biopsychosocial, emotional, cultural and economic facets, besides pointing out the needs of adaptation of these places and their activities to the public. In addition it can contribute with the knowledge of relevant characteristics to increase with actions aiming at a higher number of participants, enabling social interaction in its various modes. In the perspective of collective health, investing in the quality of life of the community's elderly, in order to keep them in a position of active aging and participant in social networks should be considered as a priority to reduce the need for investments in secondary, tertiary and quaternary preventions and institutionalization.

Therefore, the present study has the purpose of evaluating the influence of the factors related to the frailty phenotype in the occurrence of this condition in participants of social groups and health promotion (SGHP) in the primary care for the elderly of Santa Cruz/RN.

\section{METHOD}

This is a descriptive, cross-sectional, association and quantitative approach study. The research was performed in three social groups and health promotion for elderly in the city of Santa Cruz, RN. The group meetings were held biweekly in the $\mathrm{BHU}$ or in community places and and are undertaken in a collaborative way by the teams of the Family Health Strategy in partnership with extension projects linked to undergraduate courses in nursing, physiotherapy and nutrition.

Thus, the purpose of these spaces is to offer encounters of experience, socialization and actions in health promotion and active aging. The elderly perform a series of activities, such as physical exercises, workshops, community therapy, rounds of conversation and social events; besides receiving guidance and support from different professionals and students in the health area.
Thus, the study population covered all the elderly people attending the meetings. The following inclusion criteria were adopted: the elderly needed to be active participants of GCPS; both genders, aged 60 years or older and who were fully cognitively able. We considered exclusion criteria: elderly who were not very cooperative with the research, with cognitive deficit traced by the Mini Mental State Examination, with exacerbation of some inflammatory pathology, severely communicable disease, in chemotherapeutic or radiotherapeutics treatment, orthopedic fractures and/or neurological or limiting rheumatic disease. No elderly were excluded, totaling a sample of 60 individuals.

The study was authorized by the Animal Research Ethics Committee (experimental studies) or in Human Beings through the CAAE: 42298914.5 .0000 .5568$.

To obtain the data, preliminary cognitive screening was performed, followed by a semi-structured interview with socio-demographic items and related to the self-reported indicators of frailty. Then, a direct evaluation of the criteria related to the fragility phenotype was carried out ${ }^{(2)}$ :

- Unintentional weight loss ( $\geq 4.5 \mathrm{~kg}$ or $\geq 5 \%$ of weight of the previous year);

- Decrease in grip force in the Manual Dynamometer Jamar ${ }^{\circledR}$ (dominant hand) with cutoff adjusted for gender and BMI;

- Exhaustion, by self-report of fatigue: "I felt that I had to make an effort to do usual tasks" and "I could not carry my things" of the Center for Epidemiological Studies - Depression (CES-D). The elderly who scored three or four on any of the questions fulfilled the criterion.

- Low level of physical activity by Minessota Leisure Time Activity adapted version for Brazil(11), considering as the fragility criterion the energy expenditure lower than $383 \mathrm{kcal}$ (male) and $270 \mathrm{kcal}$ (female) per week;

- Decreased gait speed calculated through the time in seconds spent to cover 4.6 meters, adjusted by gender and height.

With the phenotype, the elderly are considered fragile if they present three or more criteria, pre-fragile presenting one or two and non-fragile when no positive item is presented..$^{(2,7,9)}$

Statistical analysis was performed in a descriptive way. To verify the normality of the distribution was used the Shapiro-Wilk test. Pearson's Chi-square test verified the association of frailty profiles and sociodemographic variables. To determine the association of fragility phenotype characteristics in the pre-fragile and non-fragile groups was used Fisher's exact test. The calculations were performed in the SPSS program for Windows, with statistical significance level of 0.05 . 


\section{RESULTS}

The mean age of the sample was 66.1 years $(S D=5.08)$. Most (53.3\%) are in the age group of 60-69 years, doesn't have a partner $(63.4 \%)$ and are illiterate $(58.3 \%)$. In the mentioned morbidity, $42(70 \%)$ reported some morbidity and hypertension was more prevalent in the sample (53.3\%), followed by diabetes (20\%) and osteoporosis (18.3\%). Only 1 elderly (1.7\%) already needed institutionalization, while $9(15 \%)$ required hospitalization in the 1 -year period up to the time of interview due to lack of control of blood pressure (Table 1).

Analyzing data on the fragility phenotype (Table 2), the data that showed significant correlation were unintentional weight loss (0.017), exhaustion $\left(<0.001^{*}\right)$ and slowness in gait $(<0.001 *)$. No elderly showed muscle weakness according to the dynamometry test in the time of evaluation and $20 \%$ of the elderly had low level of physical activity, i.e., they did not exercise.

In accordance with the Fried et al (2011), 4 elderly were classified as fragile, and were not described in the table below due to the infeasibility of comparing the data of only 4 elderly. Analyzing the confidence interval (Table 3), we observed that the decrease in gait speed, exhaustion, low level of physical activity and unintentional weight loss are associated with a higher prevalence of pre-frailty. Of these, the reduction of gait speed presented an additional risk of $78 \%$ for the development of pre-fragility.

\section{DISCUSSION}

The social groups and health promotion for elderly have expanded throughout Brazil and are proving to be a viable alternative to the quality of life and health promotion. In general, the motivation factor for the elderly to fit into these groups is the search for improvement in physical and mental conditions through physical exercises. Gradually, the mechanisms of adhesion are intricate in a relational network among the participants. The perception of a good quality of life is directly interlinked to self-esteem and welfare, and these factors are associated with good physical and mental health, healthy habits, leisure, spirituality and mainly the maintenance of the functional capacity of the individual. It is no coincidence that SGHP present a protective factor for several diseases prevalent in aging, such as loss of functional capacity and depression. ${ }^{(12)}$

In this context, the profile revealed in this sample is similar to some studies, presenting a higher prevalence of female (feminization of aging) and subjects with 60-69 years ${ }^{(13-16)}$, white $^{(13)}$, Without partners ${ }^{(17)}$, widowers $^{(16)}$, and retirees ${ }^{(15,16)}$.

On the other hand, another study ${ }^{(14)}$ presented an income above 3 minimum wages, the opposite of the study in question, which the majority presented income of 0 to 1 minimum salary, a fact expected by socioeconomic differences between Brazilian regions, where the South presents one of the greatest
Table 1. Socio-demographic and clinical profile of the sample by gender. Santa Cruz/RN, 2015.

\begin{tabular}{|c|c|c|}
\hline \multirow{2}{*}{ Characteristics } & \multicolumn{2}{|c|}{ Total } \\
\hline & $n(60)$ & $\%$ \\
\hline \multicolumn{3}{|l|}{ Gender } \\
\hline Female & 46 & $76.6 \%$ \\
\hline Male & 14 & $23.4 \%$ \\
\hline \multicolumn{3}{|l|}{ Age Group } \\
\hline $60-69$ years & 32 & $53.3 \%$ \\
\hline 70-79 years & 26 & $43.3 \%$ \\
\hline 80 years and over & 02 & $3.4 \% \%$ \\
\hline \multicolumn{3}{|l|}{ Race/color } \\
\hline White & 32 & $53.3 \%$ \\
\hline Black & 16 & $26.7 \%$ \\
\hline Brown & 12 & $20 \%$ \\
\hline \multicolumn{3}{|l|}{ Marital status } \\
\hline Married & 21 & $35 \%$ \\
\hline Single & 07 & $11.6 \%$ \\
\hline Widower & 27 & $45 \%$ \\
\hline Divorced & 05 & $8.4 \%$ \\
\hline \multicolumn{3}{|l|}{ Marital status } \\
\hline Accompanied & 22 & $36.6 \%$ \\
\hline Alone & 38 & $63.4 \%$ \\
\hline \multicolumn{3}{|l|}{ Schooling } \\
\hline Illiterate & 35 & $58.3 \%$ \\
\hline Full Primary School & 20 & $33.3 \%$ \\
\hline High School & 05 & $8.4 \%$ \\
\hline Higher Education & - & - \\
\hline \multicolumn{3}{|l|}{ Income** } \\
\hline 0 to 1 minimum wage & 45 & $75 \%$ \\
\hline 1 to 3 minimum wage & 15 & $25 \%$ \\
\hline \multicolumn{3}{|l|}{ Number of comorbidities } \\
\hline 0 & 18 & $30 \%$ \\
\hline 1 & 16 & $26.7 \%$ \\
\hline 2 or more & 26 & $43.3 \%$ \\
\hline \multicolumn{3}{|l|}{ BMI* } \\
\hline Underweight & 01 & $1.7 \%$ \\
\hline Eutrophic & 21 & $32 \%$ \\
\hline Overweight & 38 & $63.3 \%$ \\
\hline \multicolumn{3}{|l|}{ Hypertension } \\
\hline Yes & 32 & $53.3 \%$ \\
\hline No & 28 & $46.7 \%$ \\
\hline \multicolumn{3}{|l|}{ Diabetes } \\
\hline Yes & 12 & $20 \%$ \\
\hline No & 48 & $80 \%$ \\
\hline \multicolumn{3}{|l|}{ Osteoporosis } \\
\hline Yes & 11 & $18.3 \%$ \\
\hline No & 49 & $81.7 \%$ \\
\hline \multicolumn{3}{|l|}{ Institutionalization $* * *$} \\
\hline Already needed & 01 & $1.7 \%$ \\
\hline Never needed & 59 & $98.3 \%$ \\
\hline \multicolumn{3}{|l|}{ Hospitalization*** } \\
\hline Already needed & 09 & $15 \%$ \\
\hline Never needed & 51 & $85 \%$ \\
\hline
\end{tabular}

*WHO: underweight (BMI < 18.5), eutrophic (18.5 $\leq$ BMI $\leq 24.9)$, overweight (IMC > 25). $* *$ Value of minimum wage in 2015: R\$788.00. ${ }^{* * *}$ Data referenced one year prior to the collection. SOURCE: elaborated by the author 
Table 2. Distribution of the frequency of frailty phenotype items in the elderly sample of Santa Cruz, Rio Grande do Norte, Brazil.

\begin{tabular}{|c|c|c|c|c|c|}
\hline \multirow{3}{*}{ Phenotype items } & \multicolumn{3}{|c|}{ Frailty } & \multirow{3}{*}{$\begin{array}{l}\text { Total } \\
\text { n (\%) }\end{array}$} & \multirow{3}{*}{ Pearson's chi-square } \\
\hline & Fragile & Pre-fragile & Non-fragile & & \\
\hline & n (\%) & n (\%) & n (\%) & & \\
\hline Unintentional weight loss & & & & & $0,017^{*}$ \\
\hline Yes & $3(75 \%)$ & $11(22.4 \%)$ & 0 & 14 & \\
\hline No & $1(25 \%)$ & $38(77.6 \%)$ & $7(100 \%)$ & 46 & \\
\hline Exhaustion & & & & & $<0.001^{*}$ \\
\hline Sim & $4(100 \%)$ & $10(20.4 \%)$ & 0 & 14 & \\
\hline Não & 0 & $39(79.6 \%)$ & $7(100 \%)$ & 46 & \\
\hline Low level of physical activity & & & & & 0.135 \\
\hline Yes & $2(50 \%)$ & $10(20.4 \%)$ & 0 & 12 & \\
\hline No & $2(50 \%)$ & 39 (79.6\%) & $7(100 \%)$ & 48 & \\
\hline Slow gait & & & & & $<0.001^{*}$ \\
\hline Yes & $4(100 \%)$ & $40(81.6 \%)$ & 0 & 44 & \\
\hline No & 0 & $9(18.4 \%)$ & $7(100 \%)$ & 16 & \\
\hline Muscle weakness & & & & & - \\
\hline Yes & 0 & 0 & 0 & 0 & \\
\hline No & $4(100 \%)$ & 49 (100\%) & $7(100 \%)$ & 16 & \\
\hline
\end{tabular}

* Significance in the Pearson's chi-square test

SOURCE: elaborated by the author

Table 3. Relation of the characteristics of the frailty phenotype with the pre-fragile and non-fragile groups

\begin{tabular}{|c|c|c|c|c|}
\hline \multirow{2}{*}{ Category } & Pre-fragile & Non-fragile & \multirow{2}{*}{$x^{2}$} & \multirow{2}{*}{$\mathrm{RR}(\mathrm{Cl} 95)$} \\
\hline & $\mathrm{N}=49(\%)$ & $\mathrm{N}=7(\%)$ & & \\
\hline Reduction in the gait speed & & &, 000 & $1,78(1,15-2,74)$ \\
\hline Yes & $40(81.6 \%)$ & 0 & & \\
\hline No & $9(18.4 \%)$ & $7(100 \%)$ & & \\
\hline Reduction of the strength & & & - & - \\
\hline Yes & 0 & 0 & & \\
\hline No & $49(100 \%)$ & $7(100 \%)$ & & \\
\hline Exhaustion & & & .231 & $1.17(1.04-1.3)$ \\
\hline Yes & $10(20.4 \%)$ & 0 & & \\
\hline No & $39(79.6 \%)$ & $7(100 \%)$ & & \\
\hline Low level of physical activity & & & .231 & $1.17(1.04-1.3)$ \\
\hline Yes & $10(20.4 \%)$ & 0 & & \\
\hline No & $39(79.6 \%)$ & $7(100 \%)$ & & \\
\hline Unintentional weight loss & & & .196 & $1.18(1.04-1.34)$ \\
\hline Yes & $11(22.4 \%)$ & 0 & & \\
\hline No & $38(77.6 \%)$ & $7(100 \%)$ & & \\
\hline
\end{tabular}

Gross Domestic Product (GDP) in the country, diverging from the northeast, which is the lowest. The data indicate that despite the advances, income inequality persists among Brazilian elderly, since in the Northeast, the majority of the elderly still live in households with family income lower than a minimum wage, while in the South and Southeast this quota is comparatively lower. This strengthens the evidence of the link between the socioeconomic structure and the 
state of health of the people, especially the elderly, and the contribution to the consolidation of the socio-political and cultural context as generators of poor health and health inequalities. These factors, also considered structural, are the first to influence the health of the individual, however, this influence is not direct but occurs through more specific determinants.

Regarding the referred morbidity, among the reports, as in other studies, hypertension is also present as the disease that most affects the elderly living in community ${ }^{(15,18)}$ and diabetes is also evident. ${ }^{(18)}$ Overweight was also found in another study $^{(16)}$, with 265 elderly women in Jequié/BA, showing that many elderly in the northeast are experiencing this disease.

As a result, national studies have brought similar percentages to the study in question to investigate pre-frailty and frailty in individuals over 60 years of age: a study of FIBRA ${ }^{(3)}$ in Belo Horizonte/MG with 46.3\%, 8.7\%; FIBRA ${ }^{(13)}$ in 7 Brazilian cities $51.8 \%, 9.1 \%$; in Itabira/MG(8) $64 \%$, 1.5\%. Consequently, international studies also corroborate these findings: in Lleida, Spain $^{(19)} 44.6 \%, 8.5 \%$; in Baltimore, United States of America ${ }^{(20)}$ 35\%, 3\%.

The low number of frail elderly found in the groups investigated in the present study corroborate that the diseases and incapacities of the elderly can contribute to social isolation by limiting their participation in the community and, consequently, in the groups of coexistence, in the same way as the reduced social network may exacerbate the original disability or impose new limitations on the lifestyle of elderly. ${ }^{(9)}$

Generally, the health conditions of social network participants are better and more satisfactory than those who do not participate. To that end, the social support corresponds to the exchanges involving affection, friendship and help, fostering the union of the participants of the groups in which this network is inserted. ${ }^{(10)}$ In this case, the fostered social capital may be acting as a protective factor for such an aggravation. On the other hand, the findings refer to a sentinel mainly because a significant portion of the elderly are classified as pre-fragile, i.e., a transition phase, often silent.

Among the factors related to the frailty phenotype, which refers to functional capacity, it was observed that decreased gait speed was the item of the phenotype most demarcated in others studies ${ }^{(3,5)}$ corroborating with data from this study, referring to a greater risk of pre-frailty development for those who present this characteristic. Functionally, this condition may expose the elderly to falling and not adapting to unstable ground, such as pavements and avenues.

But, the decrease in muscle strength was the most prevalent phenotype in the item ${ }^{(8)}$, the opposite of this study sample in which no elderly presented such weakness. Such phenotype can vary according to several factors, such as age and labor activities of the elderly. The majority of the sample reported working in agriculture, a fact that requires physical strength, and in this case can be a plausible justification.
The occurrence of fatigue was poorly reported by the elderly in this study, which was also not significant ${ }^{(5)}$ regarding the relation with the frailty phenotype items. It is worth noting that the majority of the elderly did not present low level of physical activity, a fact that can be correlated to the activities developed by the groups of coexistence, which involve physical exercises such as dance, stretching, resistance exercises, among others. In addition, the regular practice of physical activity is recommended and guided by all the professionals working in the groups.

Unintentional weight loss, however, presented significant statistical significance for the sample. Inactivity allows weight loss associated with sarcopenia, one of the most important factors for the fragility phenotype. As the elderly in question are active and resident in the community, this becomes a protective factor.

Social support is revealed in society as a factor protecting individuals from the deleterious effects that stressful events cause. All social interaction and physical activity performed in such networks are able to positively change the quality of life of an elderly due to expanded access to health and general guidelines on ways to live more and better, acting directly as a protector against social exclusion and problems of health. ${ }^{(10)}$

It was possible to show that the occurrence of fragility among the elderly of the analyzed coexistence groups shows levels considered as expected according to the current national literature. In addition, the hypothesis test showed that unintentional weight loss, exhaustion and slow gait speed were the most important findings of the study population. There is a need for follow-up and new studies to confirm the findings; however the results of this study may evidence a minority of the elderly participants of groups of coexistence presents the frailty phenotype, showing the importance of the performance of these groups.

\section{CONCLUSION}

The participation in groups of coexistence was shown as a protective effect, offering clues about the relevance of social networks in maintaining functional capacities and preventing fragility among elderly. On the other hand, it is not possible to infer if attending groups of coexistence contributed to the non-occurrence of frailty or if the fact of not presenting this condition contributed to the participation in the groups. In this case, participation in groups would be a marker that the elderly do not present frailty, i.e., the elderly who do not participate in groups may be exposed to the greatest risk of developing the frailty phenotype, which prevents them from participating in groups. Then, it would be necessary to investigate the reasons that prevent the participation and an incentive to the active search and capitation of new participants, so that they can experience these supposed benefits.

In the meantime, the elderly being in a condition of frailty, or even with some limitation in their functional capacities, 
tends to weaken the interaction and the affective contacts and to jeopardize the social support received, which is based on a reciprocal relationship. The prevalence of pre-frailty indicators in the investigated groups points that actions more strongly linked to the prevention of this disease should become a priority in the planning of the interventions undertaken in the groups.

The identification of the factors associated with frailty is important, since it may subsidize health care planning for the elderly in primary care, besides contributing to the discussion and understanding of the frailty in the elderly population in groups of coexistence attending primary care in the northeast and Brazil. It is suggested that longitudinal studies be performed aiming at a better understanding of the associated factors, as well as the conducting of experimental researches that analyze the behavior of modifiable factors and its relation with the frailty phenotype in the elderly population.

Finally, as limitation of the study refers to the cross-sectional design since the causality cannot be attributed. On the other hand, the use of a large and representative sample of the county contributed to the internal validity of the study, reducing the chance of occurrence of systematic errors, and the reproducibility was satisfactory.

\section{Acknowledgement}

To God, to the elderly who were the sample of the research and to the teachers who assisted in this study.

\section{AUTHORS' CONTRIBUTIONS}

BFLF: the study's principal author; DSD: Research collaborator; SDS: Research Orientation; LPBO: Research Collaborator

\section{CONFLICT OF INTEREST}

The authors declare that they have no conflicts of interest.

\section{AUTHOR DETAILS}

2 Physiotherapist, Master degree in Production Engineering, Federal University of Paraiba (UFPB), João Pessoa (PB), Brazil.

3 Professor, Federal University of Rio Grande do Norte (UFRN), Santa Cruz (RN), Brazil.

4 Physiotherapist, Doctor degree in Biotechnology, Federal Rural University of Pernambuco (UFRPE), Recife (PE), Brazil.

5 Nurse, Doctor degree in Nursing, Federal University of Santa Catarina (UFSC), Florianópolis (SC), Brazil.

\section{REFERENCES}

1. Porciúncula RCR, Carvalho EF, Barreto KML, Leite VMM. Perfil socioepidemiológico e autonomia de longevos em Recife-PE, Nordeste do Brasil. Rev. bras. geriatr. gerontol. 2014;17(2):315-325.

2. Fried LP, Tangen CM, Walston J, Newman AB, Hirsch C, Gottdiener J, et al. Frailty in older adults evidence for a phenotype. J Gerontol A Biol Sci Med Sci. 2001;56(3):M146-56.
3. Vieira RA, Guerra RO, Giacomin KC, Vasconcelos KSS, Andrade ACS, Pereira LSM, et al. Prevalência de fragilidade e fatores associados em idosos comunitários de Belo Horizonte, Minas Gerais, Brasil: dados do estudo FIBRA. Cad. Saúde Pública. 2013;29(8):1631-1643.

4. Freitas EV. Tratado de geriatria e gerontologia. Rio de Janeiro, Guanabara Koogan, 2006.

5. Nunes DP, et al. Screening for frailty in older adults using a selfreported instrument. Revista de saudepublica, v. 49, n. 2, p. 1-9, 2015. Disponível em: <http://www.scielosp.org/article_plus.php?pid=S0034$89102015000100212 \&$ tlng= pt\&lng=en>

6. Salame M, da Costa KK, Zottele LV, Muradás RR, Tierno SA, Schettinger $M R C$, et al. Sarcopenia: evaluation of different diagnostic criteria and its association with muscle strength and functional capacity. Rev. bras. geriatr. Gerontol. 2015;18(2):285-294.

7. Santos JLF, Lebrão ML. Rastreamento de fragilidade em idosos por instrumento autorreferido. Rev Saúde Pública. 2015;49(1):1-9.

8. Carmo LV, Drummond LP, Arantes PMM. Avaliação do nível de fragilidade em idosos participantes de um grupo de convivência. Fisioterapia e Pesquisa. 2011;18(1):17-22.

9. Geib LTC. Determinantes sociais da saúde do idoso Social. Ciência \& Saúde Coletiva. 2012;17(1):123-133.

10. Brito TRP, Costa RS, Pavarini SCl. Idosos com alteração cognitiva em contexto de pobreza: estudando a rede de apoio social. Revista da Escola de Enfermagem da USP. 2012;46(4):906-913.

11. Lustosa LP, Pereira DS, Dias RC, Britto RR, Parentoni AN, Pereira LSM. Tradução e adaptação transcultural do Minnesota Leisure Time Activities Questionnaire em idosos. Geriatria \& Gerontologia. 2011;5(2):57-65.

12. Borges LJ, Benedetti TRB, Xavier AJ, d'Orsi E. Fatores associados aos sintomas depressivos em idosos: estudo EpiFloripa. Rev. Saúde Pública. 2013;47(4):701-710.

13. Neri AL, Yassuda MS, Araújo LF, Eulálio MC, Cabral BE, Siqueira MEC, et al. Metodologia e perfil sociodemográfico, cognitivo e de fragilidade de idosos comunitários de sete cidades brasileiras: Estudo FIBRA. Cad. Saúde Pública. 2013;29(4):778-792.

14. Pereira KCR, Alvarez AM, Traebert JL. Contribuição das condições sociodemográficas para a percepção da qualidade de vida em idosos. Rev Bras Geriatr Gerontol. 2011;14(1):85-95.

15. Clares JWB, de Freitas MC, de Almeida PC, de Galiza FT, Queiroz TA. Perfil de idosos cadastrados numa unidade básica de saúde da família de Fortaleza-CE. Revista da Rede de Enfermagem do Nordeste-Rev Rene, 2012;12(esp):988-994.

16. Tribess S, Virtuoso Júnior JS, Petroski EL. Estado nutricional e percepção da imagem corporal de mulheres idosas residentes no nordeste do Brasil. Cienc Saude Coletiva. 2010;15(1):31-8.

17. Benedetti TRB, Mazo GZ, Borges LJ. Condições de saúde e nível de atividade física em idosos participantes e não participantes de grupos de convivência de Florianópolis. Cien Saude Colet. 2012;17(8):2087-2093.

18. Pilger C, Menon MH, Mathias TAF. Características sociodemográficas e de saúde de idosos: contribuições para os serviços de saúde. Rev. Latino-Am. Enfermagem. 2011;19(5):1230-1238.

19. Giménez PJ, Bravo MAE, Orrio CN, Satorra TB. Criterios de fragilidade del adulto mayor. Estudio piloto. Atención primaria. 2011;43(4):190-196.

20. Xue QL, Bandeen-Roche K, Varadhan R, Zhou J, Fried LP. Initial manifestations of frailty criteria and the development of frailty phenotype in the Women's Health and Aging Study II. J Gerontol A Biol Sci Med Sci. 2008 Sep;63(9):984-90. 